\title{
Epidemiological and clinical characteristics of 161 discharged cases with coronavirus disease 2019 in Shanghai, China
}

Sheng Lin ${ }^{\dagger}$, Hao Pan ${ }^{\dagger}$, Huanyu Wu ${ }^{\dagger}$, Xiao Yu, Peng Cui, Ruobing Han, Chenyan Jiang, Dechuan Kong, Yaxu Zheng, Xiaohuan Gong, Wenjia Xiao, Shenghua Mao, Bihong Jin, Yiyi Zhu and Xiaodong Sun ${ }^{*}$ (i)

\begin{abstract}
Background: In December 2019, the outbreak of coronavirus disease 2019 (COVID-19) began in Wuhan, China, and rapidly spread to other regions. We aimed to further describe the epidemiological and clinical characteristics of discharged COVID-19 cases and evaluate the public health interventions.

Methods: We collected epidemiological and clinical data of all discharged COVID-19 cases as of 17 February 2020 in Shanghai. The key epidemiological distributions were estimated and outcomes were also compared between patients whose illness were before 24 January and those whose illness were after 24 January.

Results: Of 161 discharged COVID-19 cases, the median age was 45 years, and 80 (49.7\%) cases were male. All of the cases were categorized as clinical moderate type. The most common initial symptoms were fever (85.7\%), cough (41.0\%), fatigue (19.3\%), muscle ache (17.4\%), sputum production (14.9\%), and there were six asymptomatic cases. 39 (24.2\%) cases got infected in Shanghai, and three of them were second-generation cases of Shanghai native cases. The estimated median of the time from onset to first medical visit, admission, disease confirmation, and discharge for 161 cases was 1.0 day ( $95 \% \mathrm{Cl}, 0.6-1.2), 2.0$ days ( $95 \% \mathrm{Cl}, 1.5-2.6), 5.2$ days ( $95 \% \mathrm{Cl}, 4.6-5.7), 18.1$ days ( $95 \% \mathrm{Cl}, 17.4-18.8)$, respectively. The estimated median of the time from admission to discharge was 14.0 days $(95 \% \mathrm{Cl}, 13.3-14.6)$. The time from onset to first medical visit, admission and disease confirmation were all shortened after the Shanghai's first-level public health emergency response. In Cox regression model, the significant independent covariates for the duration of hospitalization were age, the time from onset to admission and the first-level public health emergency response.

Conclusions: Local transmission had occurred in Shanghai in late January 2020. The estimated median of the time from onset to discharge of moderate COVID-19 was 18.1 days in Shanghai. Time intervals from onset to first medical visit, admission and disease confirmation were all shortened after the Shanghai's first-level public health emergency response. Age, the first-level public health emergency response and the time from onset to admission were the impact factors for the duration of hospitalization.
\end{abstract}

Keywords: Coronavirus disease 2019, Epidemiology, Clinical characteristics, Transmission, First-level public health emergency response

\footnotetext{
*Correspondence: sunxiaodong_scdc@163.com

†Sheng Lin, Hao Pan and Huanyu Wu contributed equally to this work. Shanghai Municipal Center for Disease Control and Prevention, No. 1380, West Zhongshan Road, Shanghai 200336, China
}

(C) The Author(s). 2020 Open Access This article is licensed under a Creative Commons Attribution 4.0 International License, which permits use, sharing, adaptation, distribution and reproduction in any medium or format, as long as you give appropriate credit to the original author(s) and the source, provide a link to the Creative Commons licence, and indicate if changes were made. The images or other third party material in this article are included in the article's Creative Commons licence, unless indicated otherwise in a credit line to the material. If material is not included in the article's Creative Commons licence and your intended use is not permitted by statutory regulation or exceeds the permitted use, you will need to obtain permission directly from the copyright holder. To view a copy of this licence, visit http://creativecommons.org/licenses/by/4.0/ The Creative Commons Public Domain Dedication waiver (http://creativecommons.org/publicdomain/zero/1.0/) applies to the data made available in this article, unless otherwise stated in a credit line to the data. 


\section{Background}

Coronavirus Disease 2019 (COVID-19) is an infectious disease caused by 2019 novel coronavirus (2019-nCoV). The most common signs of infection include fever, respiratory symptoms (such as cough and sputum production) and fatigue [1]. The first COVID-19 case was identified in Wuhan, China in late December 2019 [2]. The COVID-19 has rapidly spread from Wuhan to other areas [3, 4]. As of 17 February 2020, a total of 72,528 COVID-19 cases in China have been confirmed and cases have been reported in 25 countries and 5 continents internationally [5].

To curb the spread of COVID-19, the Shanghai authorities have declared the first-level public health emergency response on 24 January 2020 [6]. The measures included: travelers from Wuhan and other epidemic areas were advised to report their travel records and to conduct selfquarantine for 2 weeks to prevent community transmission; comprehensive implementation of sanitary quarantine at the entrance of Shanghai; cancellation various large public events; masks were recommended to be worn in public places; strengthened publicity of health knowledge, etc. Public health interventions played an important role in controlling the epidemic. As of 17 February, there were a total of 333 confirmed COVID-19 cases in Shanghai and 161 of them had been cured to discharge [7].

Epidemiological and clinical characteristics of 333 confirmed COVID-19 cases in Shanghai have been reported [8]. However, at present, the impact of first-level public health emergency response on the epidemic of COVID19 was not estimated and information regarding the epidemiology and clinical features of discharged COVID-19 cases is scarce [9-12]. Therefore, we provided an analysis of key epidemiological determinants and clinical characteristics of 161 discharged COVID-19 cases in Shanghai. Moreover, we described and estimated the time interval from onset to discharge, which might helpful to understanding the progression of the disease.

\section{Methods}

\section{Study design and participants}

We performed a comprehensive study of all the 161 discharge COVID-19 cases reported in Shanghai in the case reporting system as of 17 February 2020.

\section{Case definition}

All cases were tested COVID-19 positive in laboratory and diagnosed by clinical experts according to COVID19 prevention and control program (4nd ed.) 2020 [13]. The symptom severity of COVID-19 was classified into moderate, severe and critical. Moderate cases refer to those cases who have symptoms such as fever and respiratory tract symptoms, etc. and pneumonia manifestations can be seen in imaging. Severe cases refer to any of the following criteria: (i) respiratory rate $\geq 30$ breaths/ min, (ii) oxygen saturation $\leq 93 \%$ at a rest state, (iii) arterial partial pressure of oxygen $(\mathrm{PaO} 2)$ /oxygen concentration $(\mathrm{FiO} 2) \leq 300 \mathrm{mmHg}$. Critical cases refer to those cases that meeting any of the following criteria: (i) occurrence of respiratory failure requiring mechanical ventilation, (ii) presence of shock, (iii) other organ failure that requires monitoring and treatment in the ICU. The criteria of discharge included: (i) body temperature returned to normal $\left(<37.3^{\circ} \mathrm{C}\right)$ for more than 3 days, (ii) respiratory symptoms improved significantly, (iii) rRTPCR of 2019-nCoV was negative for two consecutive times (sampling interval at least 1 day).

\section{Data collection}

After cases were reported to Shanghai Municipal Centers for Disease Control and Prevention (CDC), epidemiological investigations were conducted within $2 \mathrm{~h}$. Demographic data, clinical symptoms or signs, laboratory tests during hospital admission, comorbidities, exposure history in 14 days and prevention and control measures were all collected. When cases were discharged, clinical records of discharge were also collected. The Specific information in epidemiological investigation was entered into a computerized database of Epidata software (Epidata Association) in duplicate. The data were analyzed anonymously.

\section{Laboratory testing}

The 2019-nCoV laboratory test assays were based on the Technical Guidelines for Laboratory Testing of Novel Coronavirus Pneumonia [13]. Upper or lower respiratory specimens of suspected COVID-19 cases were collected and tested for 2019-nCoV by real-time reverse-transcriptase polymerase chain reaction (rRT-PCR) assay. Tests were carried out in biosafety level two facilities at district CDCs or Municipal CDC. The case was considered as laboratory tested positive only when two targets, open reading frame $1 \mathrm{a}$ or $1 \mathrm{~b}$ (ORF1ab) and nucleocapsid protein $(\mathrm{N})$, were both positive.

\section{ORF1ab:}

Forward primer CCCTGTGGGTTTTACACTTAA; Reverse primer ACGATTGTGCATCAGCTGA; Probe 5'-VIC-CCGTCTGCGGTATGTGGAAAGG TTATGG-BHQ1-3'.

\section{N:}

Forward primer GGGGAACTTCTCCTGCTAGAAT; Reverse primer CAGACATTTTGCTCTCAAGCTG; Probe 5'-FAM- TTGCTGCTGCTTGACAGATTTAMRA-3'.

\section{Key points in epidemiology}

The Shanghai authorities have activated the first-level public health emergency response to curb the spread of COVID-19 on 24 January. So cases were divided into two groups (illness onset during 3 Jan to 24 Jan, illness onset 
during 25 Jan to $17 \mathrm{Feb})$. Estimated median intervals of onset to first medical visit, onset to admission, onset to disease confirmation, admission to discharge, and onset to discharge were obtained for the two groups, assuming that the times were $\gamma$ distributed.

\section{Statistical analysis}

We present continuous variables as medians (interquartile ranges, IQR) and compared using Wilcoxon rank-sum tests between different groups. Categorical variables were described as counts and percentages in each category, and compared using chi-square or Fisher's exact tests between different groups. Time-delay distributions (onset to first medical visit, onset to admission, onset to disease confirmation, admission to discharge, and onset to discharge) were fitted to $\gamma$ distributions by maximum likelihood estimation methods. Cox regression model was used to identify factors significantly associated with the duration of COVID-19 hospitalization. These factors included: age, gender, hightest temperature, place of infection, smoking, drinking, body mass index, white blood cell count, neutrophil count, lymphocyte count, comorbidies, time from onset to admission and first-level public health emergency response.

Analyses of the time-delay distributions were performed with R software (R Foundation for Statistical Computing). Other analyses were performed with SPSS (Statistical Package for the Social Sciences) version 16.0 software (SPSS Inc).

\section{Results}

\section{Demographic and clinical characteristics}

As of 17 February 2020, 161 confirmed COVID-19 cases had been discharged in Shanghai. The first cured case was discharged on 24 January 2020 (Fig. 1). The median age was 45 years (IQR, 34-61; range, 1-84), and four (2.5\%) were younger than 15 years. $80(49.7 \%)$ cases were male. $39(24.2 \%)$ cases got infected in Shanghai, and three of them were second-generation cases of Shanghai native cases (Table 1).

On admission, 161 were all categorized as moderate severity. The most common reported initial symptoms at illness onset were fever (138 [85.7\%]) (the median highest temperature, $38.0^{\circ} \mathrm{C}$; IQR, 37.7-38.5), cough (66 [41.0\%]), fatigue (31 [19.3\%]), muscle ache (28 [17.4\%]), sputum production (24 [14.9\%]). Less common symptoms were vomit (3 [1.9\%]), dyspnea (3 [1.9\%]), diarrhea (5 [3.1\%]) (Table 2). 107 (66.5\%) cases reported fever plus any one other symptom, and $66(41.0 \%)$ cases reported fever plus two other symptoms. 46 (28.6\%) cases had one or more basic diseases, 27 (16.8\%) cases had hypertension, 12 (7.5\%) cases had cardiovascular diseases, 9 (5.6\%) cases had diabetes.

Of 161 cases, the median white blood cell counts was $5.0 \times 10^{9} / \mathrm{L}$ (IQR, 3.8-6.2), the median neutrophil cell

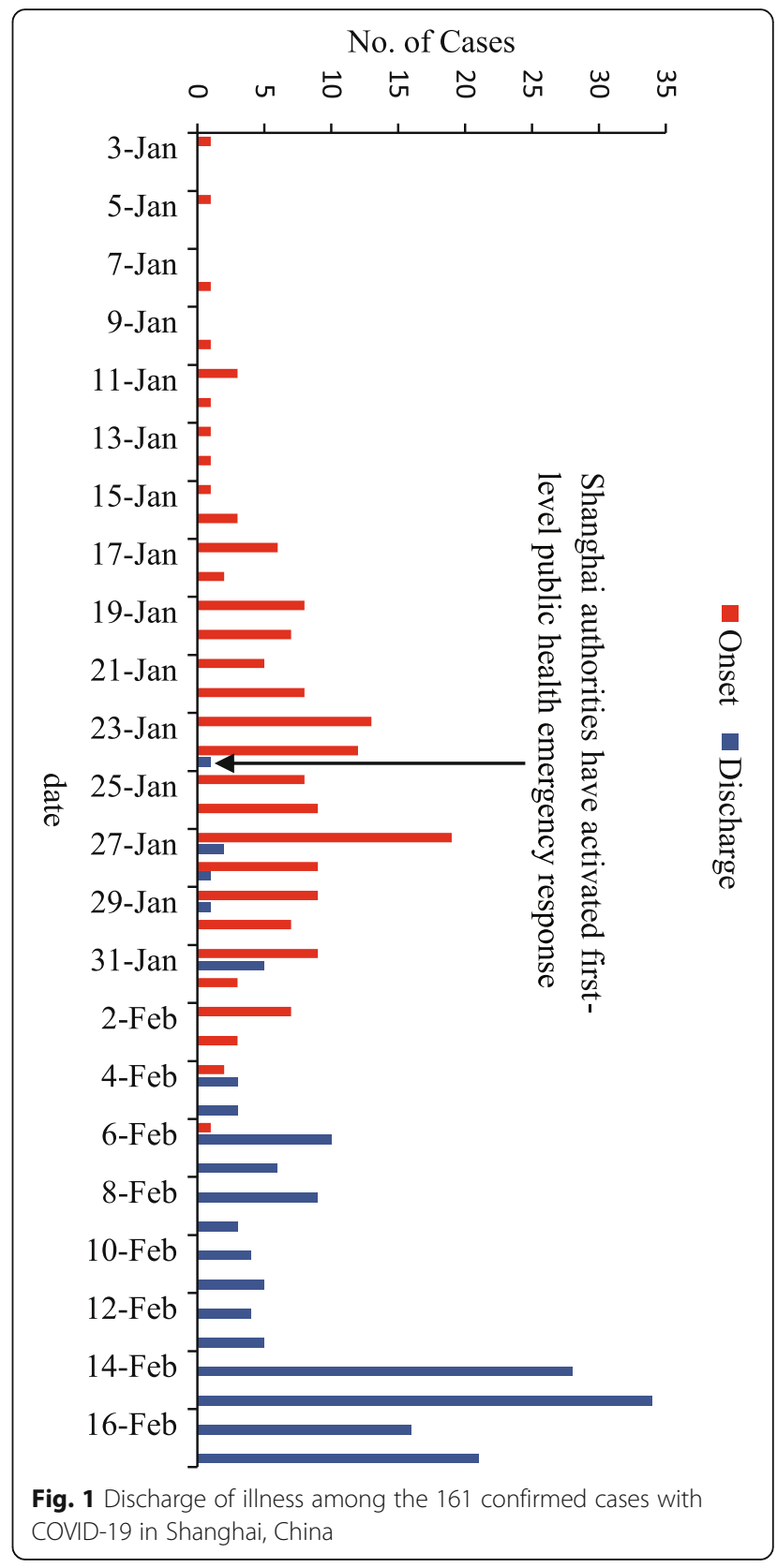

counts was $3.0 \times 10^{9} / \mathrm{L}(\mathrm{IQR}, 2.3-6.2)$, the median lymphocyte cell counts was $3.0 \times 10^{9} / \mathrm{L}(\mathrm{IQR}, 2.3-6.2)$.

\section{Key points in epidemiology}

The time from onset to discharge for 161 cases ranged from 7 to 34 days. The estimated median of the time from onset to discharge was 18.1 days (95\% CI, 17.418.8) (Table 3). The estimated median of the time from onset to discharge for 75 cases who had onset symptoms before 24 January was 20.5 days (95\% CI, 19.5-21.5), which was significantly longer than 86 cases with illness onset after 24 January, having a median of 16.2 days (95\% CI, 15.4-17.0) $(p<0.001)$ (Fig. 2). 
Table 1 Demographic characteristics of discharged COVID-19 cases in Shanghai

\begin{tabular}{|c|c|c|c|c|}
\hline \multirow[t]{2}{*}{ Category } & \multicolumn{4}{|l|}{ No. (\%) } \\
\hline & Overall $(N=161)$ & Onset before 24 January $(N=75)^{a}$ & Onset after 24 January $(N=86)$ & $\mathrm{p}$ \\
\hline Gender & & & & 0.58 \\
\hline Male & $80(49.7)$ & $39(52.0)$ & $41(47.7)$ & \\
\hline Female & $81(50.3)$ & $36(48.0)$ & $45(52.3)$ & \\
\hline Age, years & & & & 0.66 \\
\hline Median ([IQR]) & $45(34-61)$ & $45(35-60)$ & $45(32-62)$ & \\
\hline $0-14$ & $4(2.5)$ & $1(1.3)$ & $3(3.5)$ & \\
\hline $15-59$ & $113(70.2)$ & $54(72.0)$ & $59(68.6)$ & \\
\hline$\geq 60$ & $44(27.3)$ & $20(26.7)$ & $24(27.9)$ & \\
\hline Occupation & & & & 0.91 \\
\hline Staff in service industry & $55(34.2)$ & $27(36.0)$ & $28(32.6)$ & \\
\hline Retiree & $42(26.1)$ & $20(26.7)$ & $22(25.6)$ & \\
\hline Farmer/worker & $9(5.6)$ & $5(6.7)$ & $4(4.7)$ & \\
\hline Medical staff & $2(1.2)$ & $1(1.3)$ & $1(1.2)$ & \\
\hline Other & $53(32.9)$ & $22(29.3)$ & $31(36.0)$ & \\
\hline Infected Place & & & & 0.02 \\
\hline Hubei & $105(65.2)$ & $56(74.7)$ & $49(57.0)$ & \\
\hline Shanghai & $39(24.2)$ & $16(21.3)$ & $23(26.7)$ & \\
\hline Other Places & 17 (10.6) & $3(4.0)$ & $14(16.3)$ & \\
\hline Generation & & & & 0.24 \\
\hline Non-Shanghai infection & $122(75.8)$ & $59(78.7)$ & $63(73.3)$ & \\
\hline First generation & $36(22.4)$ & $10(13.3)$ & $20(23.3)$ & \\
\hline Second generation & $3(1.9)$ & $0(0.0)$ & $3(3.5)$ & \\
\hline \multicolumn{5}{|l|}{ Comorbidities } \\
\hline Any & 46 (28.6) & $22(29.3)$ & $24(27.9)$ & 0.84 \\
\hline Hypertension & $27(16.8)$ & $12(16.0)$ & $15(17.4)$ & 0.81 \\
\hline Cardiovascular disease & $12(7.5)$ & $7(9.3)$ & $5(5.8)$ & 0.40 \\
\hline Diabetes & $9(5.6)$ & $6(8.0)$ & $3(3.5)$ & 0.63 \\
\hline Digestive system disease & $9(5.6)$ & $5(6.7)$ & $4(4.7)$ & 0.83 \\
\hline Nephropathy & $4(2.5)$ & $3(4.0)$ & $1(1.2)$ & 0.52 \\
\hline Other diseases & $11(6.8)$ & $6(8.0)$ & $5(5.8)$ & 0.58 \\
\hline Drinking & & & & 0.29 \\
\hline Yes & $41(25.5)$ & $22(29.3)$ & $19(22.1)$ & \\
\hline No & $120(74.5)$ & $53(70.7)$ & $67(77.9)$ & \\
\hline Smoking history & & & & 0.15 \\
\hline Yes & $12(7.5)$ & $8(10.7)$ & $4(4.7)$ & \\
\hline No & $149(92.5)$ & $67(89.3)$ & $82(95.3)$ & \\
\hline BMI & & & & 0.69 \\
\hline$<18.5$ & $6(3.7)$ & $2(2.7)$ & $4(4.7)$ & \\
\hline $18 \cdot 5-23 \cdot 9$ & $92(57.1)$ & $45(60.0)$ & $47(54.7)$ & \\
\hline$\geq 24$ & $63(39.1)$ & $28(37.3)$ & $35(40.7)$ & \\
\hline Symptom severity & & & & - \\
\hline Moderate cases & $161(100.0)$ & 75 (100.0) & 86 (100.0) & \\
\hline Severe cases & $0(0.0)$ & $0(0.0)$ & $0(0.0)$ & \\
\hline Critical cases & $0(0.0)$ & $0(0.0)$ & $0(0.0)$ & \\
\hline
\end{tabular}


Table 2 Symptoms and the first blood routine tests of COVID-19 cases since illness onset

\begin{tabular}{|c|c|c|c|c|}
\hline & \multicolumn{4}{|l|}{ No. (\%) } \\
\hline & Overall $(N=161)$ & Onset before 24 January $(N=75)^{a}$ & Onset after 24 January $(N=86)$ & $\mathbf{p}$ \\
\hline Asymptomatic & $6(3.7)$ & $0(0.0)$ & $6(100)$ & 0.06 \\
\hline Fever & $138(85.7)$ & $68(90.7)$ & $70(81.4)$ & 0.09 \\
\hline \multicolumn{5}{|l|}{ Highest temperature, ${ }^{\circ} \mathrm{C}$} \\
\hline Median ([IQR]) & $38.0(37.5-38.3)$ & $38.0(37.6-38.4)$ & $38.0(37.3-38.2)$ & 0.27 \\
\hline$<37.3$ & $23(14.3)$ & $7(9.3)$ & $16(18.6)$ & \\
\hline $37.3-38.0$ & $74(46.0)$ & $34(45.3)$ & $40(46.5)$ & \\
\hline $38.1-39.0$ & $59(36.6)$ & $32(42.7)$ & $27(31.4)$ & \\
\hline$>39.0$ & $5(3.1)$ & $2(2.7)$ & $3(3.5)$ & \\
\hline Cough & $66(41.0)$ & $36(48.0)$ & $30(34.9)$ & 0.09 \\
\hline Fatigue & $31(19.3)$ & $19(25.3)$ & $12(14.0)$ & 0.07 \\
\hline Body aches & $28(17.4)$ & $13(17.3)$ & $15(17.4)$ & 0.99 \\
\hline Sputum production & $24(14.9)$ & $12(16.0)$ & $12(14.0)$ & 0.72 \\
\hline Headache & $24(14.9)$ & $13(17.3)$ & $11(12.8)$ & 0.42 \\
\hline Pharyngalgia & $24(14.9)$ & $13(17.3)$ & $11(12.8)$ & 0.42 \\
\hline Chill & $15(9.3)$ & $6(8.0)$ & $9(10.5)$ & 0.59 \\
\hline Snivel & $13(8.1)$ & $8(10.7)$ & $5(5.8)$ & 0.26 \\
\hline Nasal congestion & $7(4.3)$ & $3(4.0)$ & $4(4.7)$ & 0.84 \\
\hline Loss of appetite & $7(4.3)$ & $3(4.0)$ & $4(4.7)$ & 0.84 \\
\hline Chest congestion & $5(3.1)$ & $2(2.7)$ & $3(3.5)$ & 0.76 \\
\hline Diarrhea & $5(3.1)$ & $2(2.7)$ & $3(3.5)$ & 0.76 \\
\hline Nausea & $4(2.5)$ & $3(4.0)$ & $1(1.2)$ & 0.52 \\
\hline Dyspnea & $3(1.9)$ & $3(4.0)$ & $0(0.0)$ & 0.20 \\
\hline Polypnea & $3(1.9)$ & $2(2.7)$ & $1(1.2)$ & 0.48 \\
\hline Vomit & $3(1.9)$ & $3(4.0)$ & $0(0.0)$ & 0.20 \\
\hline Fever + at least 1 other & $107(66.5)$ & $56(74.7)$ & $51(59.3)$ & 0.03 \\
\hline Fever + at least 2 other & $66(41.0)$ & $38(50.7)$ & $28(32.6)$ & 0.04 \\
\hline Fever + at least 3 other & $32(19.9)$ & $18(24.0)$ & $14(16.3)$ & 0.02 \\
\hline \multicolumn{4}{|c|}{ White blood cell count, $\times 10^{9} / \mathrm{L}$ (normal range $3.5-9.5$ ) } & 0.45 \\
\hline Median ([IQR]) & $5.0(3.8-6.2)$ & $5.0(3.7-6.0)$ & $5.0(4.0-6.5)$ & \\
\hline Increased & $4(2.5)$ & $2(2.7)$ & $2(2.3)$ & \\
\hline Normal & $135(83.9)$ & $60(80.0)$ & $75(87.2)$ & \\
\hline Decreased & $22(13.7)$ & $13(17.3)$ & $9(10.5)$ & \\
\hline \multicolumn{4}{|c|}{ Neutrophil count, $\times 10^{9} / \mathrm{L}$ (normal range $1.8-6.3$ ) } & 0.62 \\
\hline Median ([IQR]) & $3.0(2.3-3.9)$ & $2.9(2.3-3.9)$ & $3.0(2.3-3.9)$ & \\
\hline Increased & $9(5.6)$ & $3(4.0)$ & $6(7.0)$ & \\
\hline Normal & $133(82.6)$ & $63(84.0)$ & $70(81.4)$ & \\
\hline Decreased & $19(11.8)$ & $9(12.0)$ & $10(11.6)$ & \\
\hline \multicolumn{4}{|c|}{ Lymphocyte count, $\times 10^{9} / \mathrm{L}$ (normal range $1.1-3.2$ ) } & 0.30 \\
\hline Median ([IQR]) & $1.3(0.9-1.7)$ & $1.2(0.8-1.7)$ & $1.3(1.0-1.7)$ & \\
\hline Increased & $3(1.9)$ & $1(1.3)$ & $2(2.3)$ & \\
\hline Normal & $93(57.8)$ & $39(52.0)$ & $54(62.8)$ & \\
\hline Decreased & 65 (40.4) & 35 (46.7) & 30 (34.9) & \\
\hline
\end{tabular}

\footnotetext{
ainclude 24 January.
} 
Table 3 Observed and maximum likelihood estimated time intervals

\begin{tabular}{|c|c|c|c|c|c|c|c|}
\hline \multirow[t]{2}{*}{ Time Intervals } & \multicolumn{2}{|c|}{ Overall $(N=161)$} & \multicolumn{2}{|c|}{ Onset before 24 January $(N=75)^{a}$} & \multicolumn{2}{|c|}{ Onset after 24 January $(N=86)$} & \multirow[t]{2}{*}{ p } \\
\hline & $\begin{array}{l}\text { Observed, } \\
\text { median (IQR) }\end{array}$ & $\begin{array}{l}\text { Estimated, } \\
\text { median }(95 \% \mathrm{Cl})\end{array}$ & $\begin{array}{l}\text { Observed, } \\
\text { median (IQR) }\end{array}$ & $\begin{array}{l}\text { Estimated, } \\
\text { median }(95 \% \mathrm{Cl})\end{array}$ & $\begin{array}{l}\text { Observed, } \\
\text { median (IQR) }\end{array}$ & $\begin{array}{l}\text { Estimated, } \\
\text { median }(95 \% \mathrm{Cl})\end{array}$ & \\
\hline $\begin{array}{l}\text { Onset to first medical } \\
\text { visit (days) }\end{array}$ & $2.0(0.0-4.0)$ & $1.0(0.6-1.2)$ & $2.0(1.0-6.0)$ & $1.7(1.1-2.5)$ & $1.0(0.0-3.0)$ & $0.6(0.3-0.8)$ & $<0.001$ \\
\hline $\begin{array}{l}\text { Onset to admission } \\
\text { (days) }\end{array}$ & $3.0(1.0-6.0)$ & $2.0(1.5-2.6)$ & $5.0(3.0-9.0)$ & $3.7(2.8-5.2)$ & $2.0(0.0-3.3)$ & $1.1(0.6-1.5)$ & $<0.001$ \\
\hline $\begin{array}{l}\text { Onset to disease } \\
\text { confirmation (days) }\end{array}$ & $5.0(3.0-9.0)$ & $5.2(4.6-5.7)$ & $8.0(5.0-11.0)$ & $7.3(6.3-8.2)$ & $4.0(2.0-6.0)$ & $3.7(3.2-4.2)$ & $<0.001$ \\
\hline $\begin{array}{l}\text { Admission to discharge } \\
\text { (days) }\end{array}$ & $14.0(11.0-17.0)$ & $14.0(13.3-14 . .6)$ & $15.0(11.0-17.0)$ & $14.4(13.3-15.4)$ & $14.0(11.0-17.0)$ & $13.7(12.9-14.4)$ & 0.19 \\
\hline $\begin{array}{l}\text { Onset to discharge } \\
\text { (days) }\end{array}$ & $19.0(15.0-22.0)$ & $18.1(17.4-18.8)$ & $21.0(19.0-23.0)$ & $20.5(19.5-21.5)$ & $17.0(14.0-19.0)$ & $16.2(15.4-17.0)$ & $<0.001$ \\
\hline
\end{tabular}

ainclude 24 January.

The estimated median of the time from onset to first medical visit for 161 cases was 1.0 day (95\% CI, $0.6-1.2)$. The estimated median of the time from onset to first medical visit for the 75 cases was 1.7 days (95\% CI, 1.1-2.5), which was significantly longer than the 86 cases with a median of 0.6 days $(95 \% \mathrm{CI}, 0.3-$ $0.8)(p<0.001)$.

The estimated median of the time from onset to admission for 161 cases was 2.0 days ( $95 \%$ CI, 1.5-2.6). The estimated median of the time from onset to admission for the 75 cases was 3.7 days (95\% CI, 2.8-5.2), which was significantly longer than the 86 cases with a median of 1.1 days (95\% CI, 0.6-1.5) $(p<0.001)$.

The estimated median of the time from onset to disease confirmation for 161 cases was 5.2 days (95\% CI, 4.6-5.7). The estimated median of the time from onset to disease confirmation for the 75 cases was 7.3 days (95\% CI, 6.3-8.2), which was significantly longer than the 86 cases with a median of 3.7 days $(95 \%$ CI, 3.2-4.2) $(p<0.001)$.

The estimated median of the time from admission to discharge for 161 cases was 14.0 days (95\% CI, $13.3-$
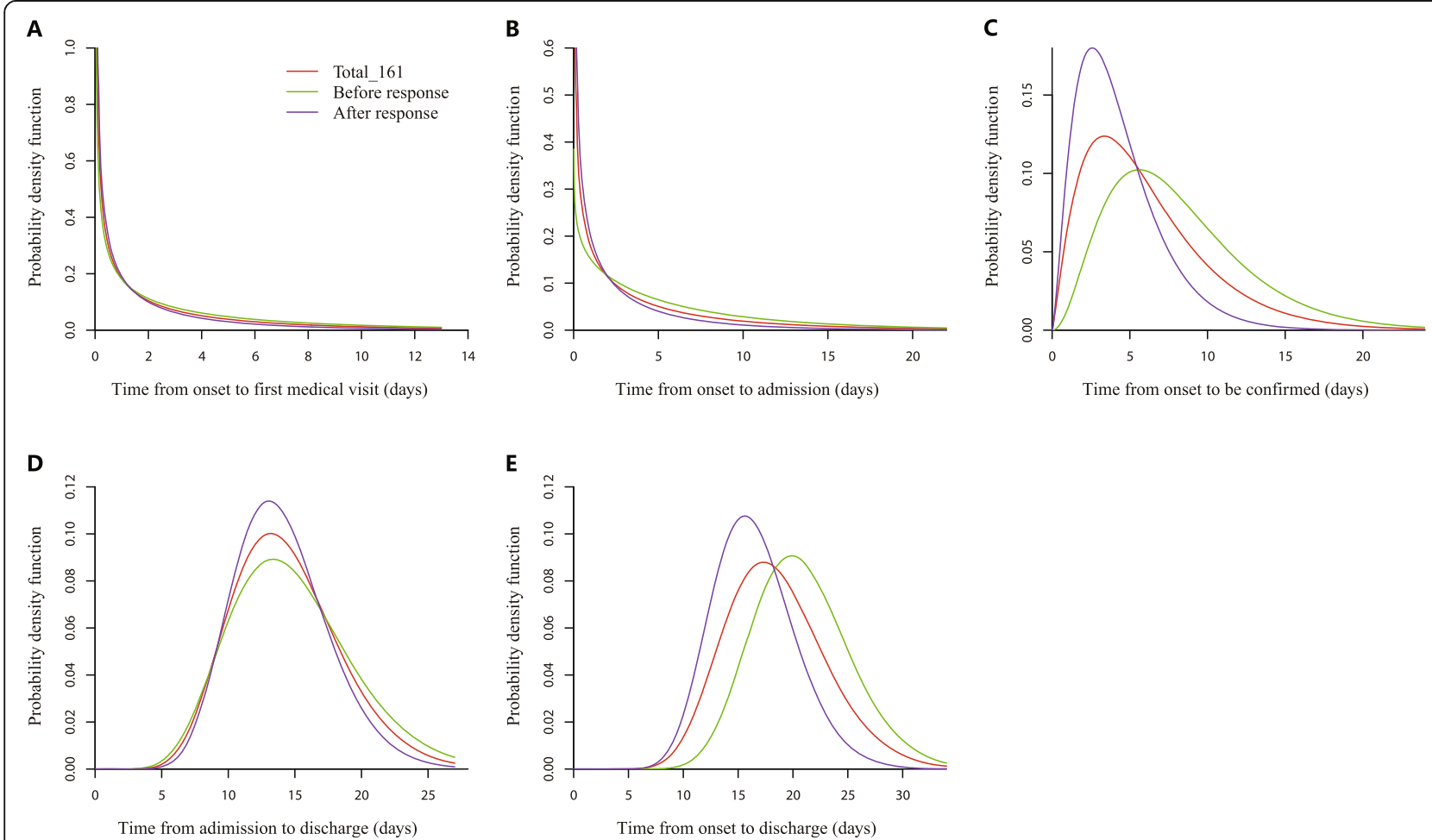

Fig. 2 Key time to event distributions. a Onset to first medical visit distribution. b Onset to admission distribution. c Onset to disease confirmation distribution. $\mathbf{d}$ Admission to discharge distribution. e Onset to discharge distribution 
14.6). The estimated median of the time from admission to discharge for the 75 cases was 14.4 days (95\% CI, 13.3-15.4), which was similar to the 86 cases with a median of 13.7 days (95\% CI, 12.9-14.4) ( $p=0.19)$.

\section{Duration of onset to discharge and hospitalization analysis}

In Cox regression model, we used discharge as the outcome variable (Tables 4 and 5). For all 161 cases, the significant independent covariates for the duration of onset to discharge were age, the time from onset to admission and the first-level public health emergency response. The significant independent covariates for the duration of hospitalization were age, the time from onset to admission and the first-level public health emergency response (Fig. 3). Potential influence which did not apparently impact duration of hospitalization was gender.

\section{Discussion}

As far as we know, this research includes the largest discharged COVID-19 case series and report an initial evaluation of the epidemiological characteristics, clinical characteristics, laboratory results, and disease course of COVID-19 cases. As of 17 February 2020, a total of 333 COVID-19 cases in Shanghai had been confirmed, of which 161 (48.3\%) cases had been cured and discharged. Among them, one (0.3\%) case died, and case fatality rate is consistent with national (except Hubei) $[14,15]$.

Among 161 discharged cases, $75.8 \%$ cases were imported to Shanghai after infection in other provinces, mainly in Hubei (65.22\%). Three of them were secondgeneration cases of Shanghai native cases, the onset of which was late January, indicating that local transmission had occurred in Shanghai in late January. The range age

Table 4 The duration of onset to discharge analyzed by multivariate Cox regression

\begin{tabular}{|c|c|c|c|c|}
\hline Factors & $\beta$ & Wald $x^{2}$ & $P$ Value & $\operatorname{Exp}(\beta)(95 \% \mathrm{Cl})$ \\
\hline \multicolumn{5}{|l|}{ First-level response } \\
\hline Onset before 24 January ${ }^{a}$ & & & & 1.0 \\
\hline Onset after 24 January & 0.8 & 18.2 & $<0.001$ & $2.3(1.6-3.4)$ \\
\hline \multicolumn{5}{|l|}{ Gender } \\
\hline Male & & & & 1.0 \\
\hline Female & -0.1 & 0.4 & 0.53 & $0.9(0.6-1.3)$ \\
\hline Age & -0.01 & 5.3 & 0.02 & $0.98(0.97-0.99)$ \\
\hline \multicolumn{5}{|l|}{ Infected Place } \\
\hline Shanghai & & 5.1 & 0.08 & 1.0 \\
\hline Hubei & -0.2 & 1.4 & 0.23 & $0.8(0.5-1.2)$ \\
\hline Other Places & 0.3 & 1.2 & 0.27 & $1.4(0.8-2.6)$ \\
\hline \multicolumn{5}{|l|}{ Comorbidities } \\
\hline No & & & & 1.0 \\
\hline Yes & -0.02 & 0.01 & 0.91 & $0.9(0.7-1.5)$ \\
\hline \multicolumn{5}{|l|}{ Smoking history } \\
\hline No & & & & 1.0 \\
\hline Yes & 0.4 & 1.5 & 0.22 & $1.5(0.8-3.0)$ \\
\hline \multicolumn{5}{|l|}{ Alcohol history } \\
\hline No & & & & 1.0 \\
\hline Yes & -0.3 & 2.0 & 0.16 & $0.7(0.5-1.1)$ \\
\hline The time from onset to admission & -0.09 & 14.1 & $<0.001$ & $0.91(0.87-0.96)$ \\
\hline \multicolumn{5}{|l|}{ BMl } \\
\hline Abnormal & & & & 1.0 \\
\hline Normal & -0.02 & 0.01 & 0.91 & $1.0(0.7-1.4)$ \\
\hline Highest temperature & -0.1 & 1.1 & 0.29 & $0.9(0.7-1.1)$ \\
\hline White blood cell count & -0.8 & 2.5 & 0.12 & $0.4(0.2-1.2)$ \\
\hline Neutrophil count & 0.9 & 2.7 & 0.10 & $2.5(0.8-7.7)$ \\
\hline Lymphocyte count & 0.9 & 1.8 & 0.18 & $2.4(0.7-8.6)$ \\
\hline
\end{tabular}

ainclude 24 January. 
Table 5 The duration of hospitalization analyzed by multivariate Cox regression

\begin{tabular}{|c|c|c|c|c|}
\hline Factors & $\beta$ & Wald $x^{2}$ & $P$ Value & $\operatorname{Exp}(\beta)(95 \% \mathrm{Cl})$ \\
\hline \multicolumn{5}{|l|}{ First-level response } \\
\hline Onset before 24 January ${ }^{a}$ & & & & 1.0 \\
\hline Onset after 24 January & 0.7 & 13.1 & $<0.001$ & $2.1(1.4-3.0)$ \\
\hline \multicolumn{5}{|l|}{ Gender } \\
\hline Male & & & & 1.0 \\
\hline Female & -0.2 & 1.5 & 0.23 & $0.8(0.5-1.2)$ \\
\hline Age & -0.02 & 5.6 & 0.02 & $0.98(0.97-0.99)$ \\
\hline \multicolumn{5}{|l|}{ Infected Place } \\
\hline Shanghai & & 4.3 & 0.12 & 1.0 \\
\hline Hubei & -0.2 & 1.4 & 0.24 & $0.8(0.5-1.2)$ \\
\hline Other Places & 0.3 & 0.9 & 0.35 & $1.3(0.7-2.5)$ \\
\hline \multicolumn{5}{|l|}{ Comorbidities } \\
\hline No & & & & 1.0 \\
\hline Yes & -0.01 & 0.002 & 0.96 & $1.0(0.7-1.5)$ \\
\hline \multicolumn{5}{|l|}{ Smoking history } \\
\hline No & & & & 1.0 \\
\hline Yes & 0.4 & 1.1 & 0.29 & $1.4(0.7-2.8)$ \\
\hline \multicolumn{5}{|l|}{ Alcohol history } \\
\hline No & & & & 1.0 \\
\hline Yes & -0.2 & 1.2 & 0.26 & $0.8(0.5-1.2)$ \\
\hline The time from onset to admission & 0.1 & 28.9 & $<0.001$ & $1.1(1.1-1.2)$ \\
\hline \multicolumn{5}{|l|}{ BMI } \\
\hline Abnormal & & & & 1.0 \\
\hline Normal & -0.1 & 0.1 & 0.74 & $0.9(0.7-1.3)$ \\
\hline Highest temperature & -0.2 & 1.7 & 0.19 & $0.8(0.6-1.1)$ \\
\hline White blood cell count & -0.9 & 2.8 & 0.09 & $0.4(0.1-1.2)$ \\
\hline Neutrophil count & 1.0 & 3.0 & 0.08 & $2.7(0.9-8.3)$ \\
\hline Lymphocyte count & 0.8 & 1.6 & 0.20 & $2.3(0.6-8.5)$ \\
\hline
\end{tabular}

a include 24 January.

of the cases was 1 to 84 years, indicating that all age groups are susceptible to the 2019-nCoV.

Common symptoms at onset of illness were fever, dry cough and fatigue. However, a significant proportion of cases presented initially with atypical symptoms, such as vomit, diarrhea and dyspnea. There were a certain proportion (14.4\%) of cases without fever, if screening is focused on the detection of fever, some cases may be missed. The study found that there were six asymptomatic cases of COVID-19, which indicates that asymptomatic infections or pre-symptomatic infections is possible. The asymptomatic infections make it difficult to recognize illness and difficult to quickly and effectively isolate asymptomatic and pre-symptomatic cases, increasing the effective infectious period and the risk for transmission.

In Nanshan Chen et al. study [11], mainly in moderate patients infected with 2019-nCoV, 35\% of patients had lymphocytopenia, and lymphocytopenia occurred in more than $80 \%$ of critically ill patients in Xiaobo Yang et al. study [9], indicating that the severity of lymphocytopenia reflects the severity of 2019-nCoV infection. Lymphocytopenia occurred in more than $40 \%$ of cases in our study. In the Cox regression model, the lower the lymphocyte count, the longer the duration of hospitalization, but there is no statistical significance, our sample size may be limited to finding a statistical significance.

The estimated median of the time from onset to the first medical visit, admission, disease confirmation was 1 day, 2 days and 5.2 days, respectively. After first-level public health emergency response, the time were reduced to 0.6 days, 1.1 days, and 3.7 days, respectively, which was significantly shorter than that before first-level public health emergency response (1.7 days, 3.7 days, and 7.3 days, respectively). This indicates that the early identification, isolation and 

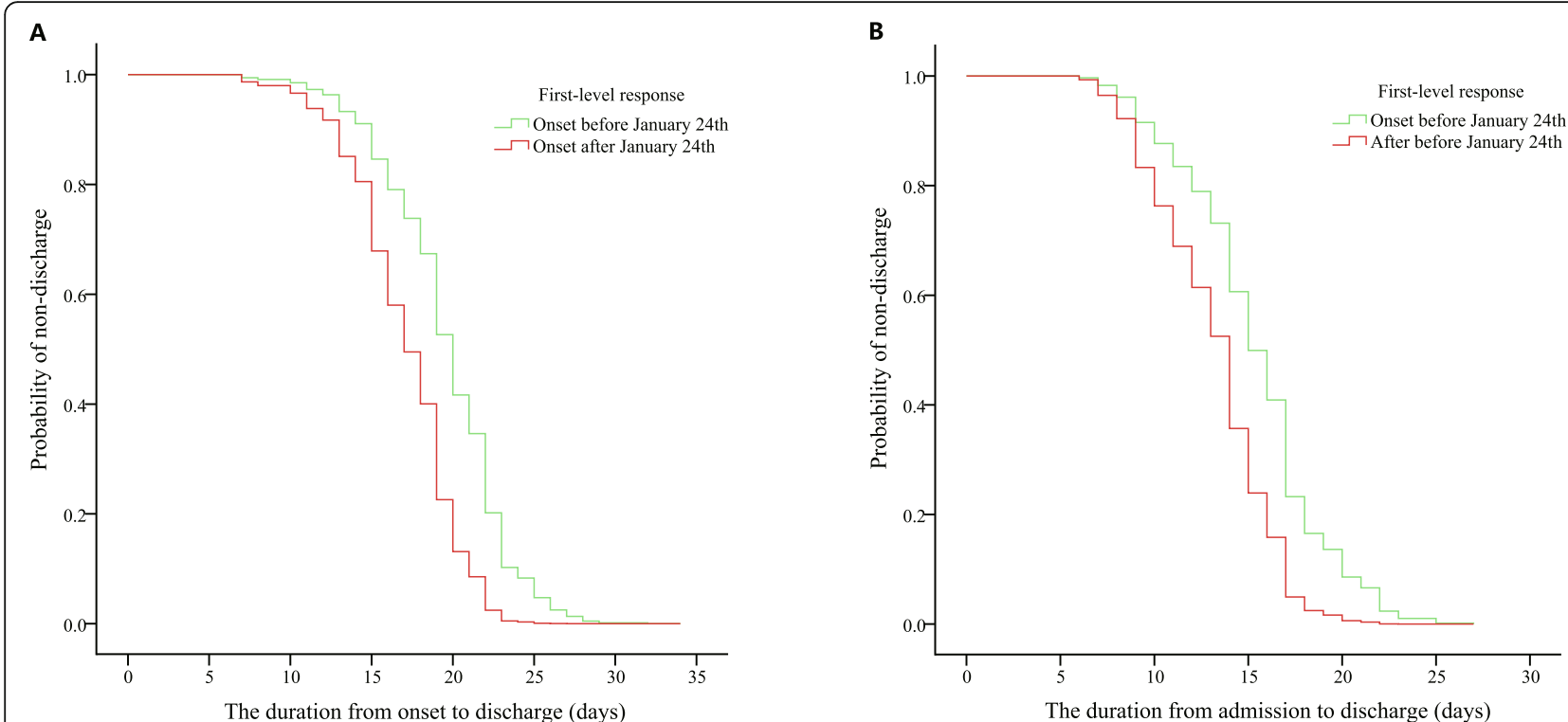

Fig. 3 Cox regression model. a First-level public health emergency response impacts the duration of onset to discharge. b First-level public health emergency response impacts the duration of admission to discharge

confirmation of cases with COVID-19 have been accelerated after the first-level public health emergency response. Shortening the duration of onset to admission does not seem to impact clinical outcomes $[16,17]$. However, shortening the duration of onset to admission facilitates quarantine and reduces the risk of transmission, and the effective communicable period. And any additional shortening of the duration that symptomatic cases are in the community will bring about further benefits at the whole crowd level.

Quarantine is a traditional and yet the most effective measure to control an epidemic. Because there is no specific vaccine or cure against 2019-nCoV infections, standard public health emergency measures usually prove most efficient, including isolating the sources of infection, interrupting or cutting off transmission routes, and special care for the most susceptible people. And the COVID-19 epidemic has shown that the essential for risk disclosure that will warn and inform the citizens, in such a way that will enhance personal protection, without triggering raised fear and anxiety, as an essential part of COVID-19 epidemic control. A change in disease risk awareness would potentially bring about an increase in early reporting of COVID-19.

Cox regression analysis showed that the elder the case, the longer the duration of hospitalization. The possible explanations were that the younger case has higher recovery ability after infection with 2019-nCoV, and the elder case has a higher proportion of comorbidities. We review previous studies that found a greater number of male than female $[11,18,19]$, but our research shows that there was no significant difference in the course of disease between male and female. After first-level public health emergency response, the duration of hospitalization was shorter.
Shortening the time from initial symptoms to admission does not decrease the duration of hospitalization for moderate COVID-19 cases. More generally, the average time from onset to discharge was 19 days. One reason may be that there is no specific cure or vaccine against 2019$\mathrm{nCoV}$ infections except for meticulous supportive. Another reason may be that it may indicates that moderate COVID-19 is self-limited disease.

This study has several limitations. First, only three of 161 cases had short and defined periods of exposure to known COVID-19 cases, so we did not estimate the distribution of the incubation period, the time from infection to the onset of symptoms of COVID-19. Second, the symptom severity of the discharged cases was moderate pneumonia, so we are unable to estimate severe or critical pneumonia.

\section{Conclusions}

In conclusion, local transmission had occurred in Shanghai in late January 2020. The estimated median of the time from onset to discharge of moderate COVID-19 was 18.1 days in Shanghai. Time intervals from onset to first medical visit, admission and disease confirmation were all shortened after Shanghai's first-level public health emergency response. Age, first-level public health emergency response and the time from onset to admission were the impact factors for the duration of hospitalization. Male and female have the same course of disease.

\section{Abbreviations}

COVID-19: Coronavirus Disease 2019; 2019-nCoV: 2019 novel coronavirus; CDC: Centers for Disease Control and Prevention; rRT-PCR: Real-time reversetranscriptase polymerase chain reaction 


\section{Acknowledgments}

We thank all medical workers taking part in investigation and treatment of COVID-19 patients in Shanghai.

\section{Authors' contributions}

SXD, WHY, PH conceived the study. LS designed the study, analyzed data and wrote manuscript. YX, CP, KDC, HRB, JCY, ZYX, GXH, XWJ, MSH, JBH and ZYY were involved in collecting data and data cleaning. All authors have read and approved the final manuscript.

\section{Funding}

This work was support by a grant from Science and Technology Commission Shanghai Municipality Grant/Award Number: 20JC1410200.

\section{Availability of data and materials}

The datasets used and/or analysed during the current study are available from the corresponding author (Xiaodong Sun, sunxiaodong_scdc@163.com) on reasonable request.

\section{Ethics approval and consent to participate}

This study was reviewed and approved by Shanghai Municipal Center for Disease Control and Prevention Ethics Review Committee, which waived the written informed consent for emerging infectious diseases. The data were analyzed anonymously.

\section{Consent for publication}

Not applicable.

\section{Competing interests}

The authors declare that they have no competing interests.

Received: 10 March 2020 Accepted: 8 October 2020

Published online: 20 October 2020

\section{References}

1. World Health Organization. Question and answer on coronaviruses (COVID19). 2020. https://www.who.int/news-room/q-a-detail/q-a-coronaviruses. Accessed 20 Feb 202020.

2. Lu H, Stratton CW, Tang YW. Outbreak of pneumonia of unknown etiology in Wuhan, China: the mystery and the miracle. J Med Virol. 2020;92(4):401-2.

3. Wang D, Hu B, Hu C, Zhu F, Liu X, Zhang J, Wang B, Xiang H, Cheng Z, Xiong Y, et al. Clinical characteristics of 138 hospitalized patients with 2019 novel coronavirus-infected pneumonia in Wuhan, China. JAMA. 2020;323:1061.

4. Hui DS, I Azhar E, Madani TA, Ntoumi F, Kock R, Dar O, Ippolito G, Mchugh TD, Memish ZA, Drosten C, et al. The continuing 2019-nCoV epidemic threat of novel coronaviruses to global health - the latest 2019 novel coronavirus outbreak in Wuhan, China. Int J Infect Dis. 2020;91:264-6.

5. World Health Organization. Coronavirus disease 2019 (COVID-19) Situation reports29. https:/www.who.int/docs/default-source/coronaviruse/situation-reports/202 00218-sitrep-29-covid-19.pdf?sfursn=6262de9e_2. Accessed 20 Feb 202020.

6. Shanghai Municipal People's Government, Shanghai launched a first-level response to resolutely curb the spread of the epidemic. http://www. shanghai.gov.cn/nw2/nw2314/nw32419/nw48516/nw48539/u21aw1423526. html. Accessed 20 Feb 202020.

7. Shanghai Municipal People's Government, One new confirmed case of COVID-19 in Shanghai. http://www.shanghai.gov.cn/nw2/nw2314/nw32419/ nw48516/nw48518/u21aw1426139.html. Accessed 20 Feb 202020.

8. Yu X, Sun X, Cui P, Pan H, Lin S, Han R, Jiang C, Fang Q, Kong D, Zhu Y, et al. Epidemiological and clinical characteristics of 333 confirmed cases with coronavirus disease 2019 in Shanghai, China. TRANSBOUND EMERG DIS. 2020;67(4):1697-707.

9. Yang $X, Y u$ Y, Xu J, Shu H, Xia J, Liu H, Wu Y, Zhang L, Yu Z, Fang M, et al. Clinical course and outcomes of critically ill patients with SARS-CoV-2 pneumonia in Wuhan, China: a single-centered, retrospective, observational study. Lancet Respir Med. 2020;8:475.

10. Xu X, Wu X, Jiang X, Xu K, Ying L, Ma C, Li S, Wang H, Zhang S, Gao H, et al. Clinical findings in a group of patients infected with the 2019 novel coronavirus (SARS-Cov-2) outside of Wuhan, China: retrospective case series. BMJ. 2020;368:m606.

11. Chen N, Zhou M, Dong X, Qu J, Gong F, Han Y, Qiu Y, Wang J, Liu Y, Wei Y, et al. Epidemiological and clinical characteristics of 99 cases of 2019 novel coronavirus pneumonia in Wuhan, China: a descriptive study. Lancet. 2020; 395(10223):507-13.

12. Li Q, Guan X, Wu P, Wang X, Zhou L, Tong Y, Ren R, Leung KSM, Lau EHY, Wong JY, et al. Early transmission dynamics in Wuhan, China, of novel coronavirus-infected pneumonia. N Engl J Med. 2020;382:1199.

13. National Health Commission of the People's Republic of China, New coronavirus pneumonia prevention and control program (4nd ed.) (in Chinese). 2020. http://www.nhc.gov.cn/yzygj/s7653p/202001/4294563ed35 b43209b31739bd0785e67.shtml. Accessed 20 Feb 202020.

14. Novel Coronavirus Pneumonia Emergency Response Epidemiology T. The epidemiological characteristics of an outbreak of 2019 Novel coronavirus diseases (COVID-19) in China. Zhonghua Liu Xing Bing Xue Za Zhi. 2020;41(2):145-51.

15. Wu Z, McGoogan JM. Characteristics of and important lessons from the coronavirus disease 2019 (COVID-19) outbreak in China: summary of a report of 72314 cases from the Chinese Center for Disease Control and Prevention. JAMA. 2020;323:1239.

16. Donnelly CA, Ghani AC, Leung GM, Hedley AJ, Fraser C, Riley S, Abu-Raddad $L J, H o L$, Thach T, Chau P, et al. Epidemiological determinants of spread of causal agent of severe acute respiratory syndrome in Hong Kong. Lancet. 2003:361(9371):1761-6

17. Leung GM, Hedley AJ, Ho LM, Chau P, Wong IO, Thach TQ, Ghani AC, Donnelly CA, Fraser C, Riley S, et al. The epidemiology of severe acute respiratory syndrome in the 2003 Hong Kong epidemic: an analysis of all 1755 patients. Ann Intern Med. 2004;141(9):662-73.

18. Huang C, Wang Y, Li X, Ren L, Zhao J, Hu Y, Zhang L, Fan G, Xu J, Gu X, et al. Clinical features of patients infected with 2019 novel coronavirus in Wuhan. China The Lancet. 2020;395(10223):497-506.

19. Guan WJ, Ni ZY, Hu Y, Liang WH, Ou CQ, He JX, Liu L, Shan H, Lei CL, Hui D, et al. Clinical characteristics of coronavirus disease 2019 in China. N Engl J Med. 2020;382:1708

\section{Publisher's Note}

Springer Nature remains neutral with regard to jurisdictional claims in published maps and institutional affiliations.

Ready to submit your research? Choose BMC and benefit from:

- fast, convenient online submission

- thorough peer review by experienced researchers in your field

- rapid publication on acceptance

- support for research data, including large and complex data types

- gold Open Access which fosters wider collaboration and increased citations

- maximum visibility for your research: over $100 \mathrm{M}$ website views per year

At $\mathrm{BMC}$, research is always in progress.

Learn more biomedcentral.com/submissions 